\title{
Plant-Based Phytochemical Screening by Targeting Main Protease of SARS-CoV-2 to Design Effective Potent Inhibitors
}

\author{
Shafi Mahmud ${ }^{1,+}+\mathbb{D}$, Suvro Biswas ${ }^{2,+}{ }^{,}$Gobindo Kumar Paul ${ }^{1}$, Mohasana Akter Mita ${ }^{2}$, Maria Meha Promi ${ }^{2}$, \\ Shamima Afrose ${ }^{2}$, Md. Robiul Hasan ${ }^{2}$, Shahriar Zaman ${ }^{1}$, Md. Salah Uddin ${ }^{1}$, Kuldeep Dhama ${ }^{3}$, \\ Talha Bin Emran ${ }^{4, *(\mathbb{D}, \text { Md. Abu Saleh }}{ }^{1, *(1)}$ and Jesus Simal-Gandara ${ }^{5, *(\mathbb{C})}$
}

Citation: Mahmud, S.; Biswas, S.; Paul, G.K.; Mita, M.A.; Promi, M.M.; Afrose, S.; Hasan, M.R.; Zaman, S.; Uddin, M.S.; Dhama, K.; et al. PlantBased Phytochemical Screening by Targeting Main Protease of SARSCoV-2 to Design Effective Potent Inhibitors. Biology 2021, 10, 589. https://doi.org/10.3390/ biology10070589

Academic Editor: Henry Yu-Keung Mok

Received: 26 May 2021

Accepted: 22 June 2021

Published: 26 June 2021

Publisher's Note: MDPI stays neutral with regard to jurisdictional claims in published maps and institutional affiliations.

Copyright: (c) 2021 by the authors. Licensee MDPI, Basel, Switzerland. This article is an open access article distributed under the terms and conditions of the Creative Commons Attribution (CC BY) license (https:// creativecommons.org/licenses/by/ $4.0 /)$.
1 Microbiology Laboratory, Department of Genetic Engineering and Biotechnology, University of Rajshahi, Rajshahi 6205, Bangladesh; shafimahmudfz@gmail.com (S.M.); gobindokumar38@gmail.com (G.K.P.); szaman@ru.ac.bd (S.Z.); salim.geb@ru.ac.bd (M.S.U.)

2 Department of Genetic Engineering and Biotechnology, University of Rajshahi, Rajshahi 6205, Bangladesh; suvrobiswas0@gmail.com (S.B.); mohasanamita26@gmail.com (M.A.M.); meha.mitsa@gmail.com (M.M.P.); shamimaafrose.ru@gmail.com (S.A.); rhonanik7@gmail.com (M.R.H.)

3 Division of Pathology, Indian Veterinary Research Institute, Izatnagar, Bareilly 243122, UP, India; kdhama@rediffmail.com

4 Department of Pharmacy, BGC Trust University Bangladesh, Chittagong 4381, Bangladesh

5 Nutrition and Bromatology Group, Department of Analytical and Food Chemistry, Faculty of Food Science and Technology, University of Vigo-Ourense Campus, E32004 Ourense, Spain

* Correspondence: talhabmb@bgctub.ac.bd (T.B.E.); saleh@ru.ac.bd (M.A.S.); jsimal@uvigo.es (J.S.-G.); Tel.: +880-1-819-942-214 (T.B.E.); +880-1-716-731-747 (M.A.S.); +34-988-387-000 (J.S.-G.)

+ These authors contributed equally to this work.

Simple Summary: Virtual screening schemes, including molecular docking in conjunction with molecular dynamics simulation, were accomplished, as they extend an ample opportunity to screen plausible inhibitors of the main protease from an extensive phytochemical library. The preferential phytochemicals were retrieved from Asian plants through the data mining procedure and comprehensive literature study. The three preeminent reliable phytochemical exhibited toxicity by no means during the scrutinization of ADMET prominences. Moreover, pharmacologically distinguishing characteristics and the biological activity of the lead phytochemicals were satisfying as a repurposing antiviral drug contender. Additionally, the molecular dynamics simulation exhibited thermal stability and a stable binding affinity of the protein-compound complex that refers to the appreciable efficacy of the lead optimization. Therefore, the preferable phytochemicals are worth substantial evaluation in the biological laboratory to recommend plausible antiviral drug contenders.

Abstract: Currently, a worldwide pandemic has been declared in response to the spread of coronavirus disease 2019 (COVID-19), a fatal and fast-spreading viral infection caused by severe acute respiratory syndrome coronavirus 2 (SARS-CoV-2). The low availability of efficient vaccines and treatment options has resulted in a high mortality rate, bringing the world economy to its knees. Thus, mechanistic investigations of drugs capable of counteracting this disease are in high demand. The main protease (Mpro) expressed by SARS-CoV-2 has been targeted for the development of potential drug candidates due to the crucial role played by $\mathrm{M}^{\text {pro }}$ in viral replication and transcription. We generated a phytochemical library containing 1672 phytochemicals derived from 56 plants, which have been reported as having antiviral, antibacterial, and antifungal activity. A molecular docking program was used to screen the top three candidate compounds: epicatechin-3-O-gallate, psi-taraxasterol, and catechin gallate, which had respective binding affinities of $-8.4,-8.5$, and $-8.8 \mathrm{kcal} / \mathrm{mol}$. Several active sites in the targeted protein, including Cys145, His41, Met49, Glu66, and Met165, were found to interact with the top three candidate compounds. The multiple simulation profile, root-mean-square deviation, root-mean-square fluctuation, radius of gyration, and solvent-accessible surface area values supported the inflexible nature of the docked protein-compound complexes. The toxicity and carcinogenicity profiles were assessed, which showed that epicatechin-3-O-gallate, psi-taraxasterol, and catechin gallate had favorable pharmacological properties with no adverse effects. These findings 
suggest that these compounds could be developed as part of an effective drug development pathway to treat COVID-19.

Keywords: SARS-CoV-2; phytochemicals; molecular docking; ADMET; dynamics simulation

\section{Introduction}

In December 2019, approximately 41 patients were diagnosed with anomalous pneumonia of unfamiliar etiology in Wuhan City, China, and, within a relatively short time, this disease spread rapidly worldwide [1-3]. The etiology of this pneumonia, which has since been named coronavirus disease 2019 (COVID-19), was eventually identified as a novel coronavirus, which was formally designated as severe acute respiratory syndrome coronavirus 2 (SARS-CoV-2) [1]. This virus has wreaked havoc worldwide due to the scarcity of health frameworks and a lack of preparation for a disease of this scale, causing 2,470,772 deaths and infecting 111,419,939 people thus far [4].

The SARS-CoV-2 is single-stranded, positive-sense RNA (+ssRNA) viruses that belong to the Betacaronavirus ( $\beta-\mathrm{CoV}$ ) genus with a genome size that ranges from 26 to $32 \mathrm{~kb}[5]$. Coronaviruses can be classified into four genera: alpha- $\mathrm{CoV}$, beta-CoV, gamma-CoV, and delta-CoV. Among these, only the alpha- $\mathrm{CoV}$ and beta-CoV genera have been shown to infect humans $[6,7]$. Coughing, sneezing, respiratory droplets, and fomites represent the primary vectors for viral spread [8,9].

The SARS-CoV-2 genome consists of a $5^{\prime}$ methyl-guanosine cap structure, a 5'untranslated region (UTR), open reading frame (ORF), a $3^{\prime}$-UTR, and a poly-adenosine (poly-A) tail [10-12]. ORF 1ab encodes 16 nonstructural proteins (nsp 1 to nsp 16), which are indispensable for viral replication. The remainder of the genome encodes four structural proteins, membrane protein $(\mathrm{M})$, spike glycoprotein (S), envelope protein (E), and nucleocapsid protein $(\mathrm{N})$, in addition to other accessory proteins, including ORFs $3 a, 7 a / b$, 6 , and 8 [13-16].

SARS-CoV-2 invades alveolar type II cells following the interaction between the $S$ protein and the angiotensin-converting enzyme 2 (ACE-2) receptor, causing acute alveolar damage [4]. Afterward, the viral genome attaches to the host's ribosomes, resulting in the translation of large polyproteins that are later modified by proteolysis $[17,18]$. The SARS-CoV-2 genome shares approximately $96 \%$ and $80 \%$ sequence identity with the bat coronavirus (BatCoV) RaTG13 and SARS-CoV, respectively $[14,19,20]$. Pangolin-CoV has also been found to share $91.02 \%$ sequence identity with SARS-CoV-2 [21].

A cysteine protease, known as main protease $\left(\mathrm{M}^{\mathrm{pro}}\right)$, plays a central role in the post-translational modification of replicase polyproteins [14,22,23]. ORF 1ab encodes the polyproteins ppla and pplab, which are cleaved by $\mathrm{M}^{\text {pro }}$ into abundant functional units that are responsible for viral replication and transcription [14]. Mpro exhibits unique enzymatic activity and is involved in the processing of all viral polyproteins [22,24]. Following the translation of viral mRNA into polyproteins, Mpro exerts an autocleavage function that results in the mature enzyme, which then processes the polyprotein into $11 \mathrm{nsps}$ that regulate the viral replication process [25,26]. Therefore, viral polyprotein processing, viral replication, viral transcription, and viral maturation are all dependent on $\mathrm{M}^{\text {pro }}$ activity $[9,27-30]$, and the inhibition of $\mathrm{M}^{\text {pro }}$ should prevent viral replication and spread [27]. A specific Mpro inhibitor would likely be nontoxic because no human proteases share any corresponding recognition sequences with $\mathrm{M}^{\text {pro }}[27,31]$. For these reasons, SARS-CoV-2 $\mathrm{M}^{\text {pro }}$ represents a promising target for antiviral drug discovery $[25,27,32]$.

The currently available antiviral agents approved for clinical use have demonstrated limited efficacy and are associated with adverse reactions, including enhanced viral resistance following long-term therapy. By contrast, antiviral therapeutics that have been developed based on phytochemicals have been reported to have more tolerable side effects and can serve as a reliable alternative to synthetic antiviral drugs for the inhibition of viral 
replication and penetration [33-36]. In humans, 4',5-dihydroxy-3,7,3'-trimethoxyflavone demonstrated antiviral efficacy against rhinoviruses, coxsackieviruses, and picornaviruses, whereas gingerol was shown to act against the common cold virus. Myricetin can act as an antiviral phytochemical against the human immunodeficiency virus, Rhesus lymphocryptovirus, and influenza virus. Additionally, apigenin exhibits antiviral activity against Enterovirus 71, hepatitis $C$ virus, and African swine fever virus; quercetin inhibits the Epstein-Barr virus, influenza A, and rhinovirus; and curcumin has been characterized as an antiviral agent for Zika virus, chikungunya virus, herpes simplex virus, human papillomavirus, and cytomegalovirus $[33,37]$. Therefore, phytochemicals represent a plausible class of bioactive antiviral compounds that can be developed into therapeutics against various strains of SARS-CoV-2 [34].

An alkaloid named 'Quinine' is applied for Plasmodium falciparum malaria [38], whereas another phytochemical named 'Podophyllin' is utilized as pharmaceutics for treating perianal warts and external genital warts [39]. Additionally, another phytochemical-based hepatoprotective drug named 'Glycyrrhizic acid' exhibits curative effects against chronic hepatitis [40]. Notably, quinine, podophyllin, and glycyrrhizic acid have already been approved by FDA (Food and Drug Administration) for therapeutics use. Furthermore, FDA-approved antiviral drugs, including letermovir, baloxavir, marboxil, nelfinavir, and ombitasvir, are applied to treat cytomegalovirus infections, influenza, HIV infection, and hepatitis C virus (HCV) infections, respectively [41-44].

The computer-aided screening process can be a valid source to develop effective therapeutic solution against target protein. Here, a deep literature mining was conducted to enlist effective phytochemicals candidates which finally screened against the target main protease of SARS-CoV-2. The hit molecules obtained from molecular docking were finally assessed in molecular dynamics simulation due to low efficacy in binding mode, motion effect, and solvation effect in molecular docking pipelines. These compound can be further utilized in in vitro and in vivo experiments against antiviral protein of SARS-CoV-2.

\section{Materials and Methods}

\subsection{Protein Preparation}

The three-dimensional (3D) crystal structure (PDB ID: 6LU7; Method: X-ray diffraction; Resolution: $2.16 \AA$; Organism: SARS-CoV-2) of the SARS-CoV-2 main protease $\left(\mathrm{M}^{\mathrm{pro}}\right)$ was retrieved from the Protein Data Bank (PDB) database maintained by Research Collaboratory for Structural Bioinformatics (RCSB) [45]. Water molecules and every heteroatom in the protein structure were removed using Pymol [46] and Discovery Studio software [47]. The cleaned crystal structure was then optimized, verified, and energy-minimized using the GROMOS 43B1 force field via the Swiss-PDB viewer [48].

\subsection{Ligand Preparation}

A total of 1672 compounds were included in the screening (Tables S1-S3), encoded by various plants, after a profound literature review. The PubMed, Google Scholar, PubChem, Phytochemical database, Dr. Duke database, IMPPAT, and Google search were employed to enlist the phytochemicals presents in the plant compounds. Furthermore, these data sets were also validated by examining the gas chromatography-mass spectroscopy and liquid chromatography-mass spectroscopy data from the literature. The duplicates were removed to maintain the accuracy of the data sets. The 3D structures of these molecules were extracted from the PubChem database [49]. The ligand structures were optimized, cleaned, prepared, and minimized using the $\mathrm{mmff} 94$ force field [50], using the optimization algorithm with the steepest descent and a total number of 2000 minimization steps.

\subsection{Molecular Docking Study}

Molecular docking was performed via the PyRx Virtual Screening Tool [51] to explore all possible orientations, conformations, and binding affinities for the ligand with the potential $\mathrm{M}^{\text {pro }}$ binding sites. All ligand free energy values were minimized using the universal 
force field (UFF), combined with the conjugate gradient algorithm and 2000 minimization steps. All ligands were converted to PDBQT format to prepare them in an acceptable format for docking in AutoDock Vina. The docking was configured as protein-fixed and ligand-flexible, allowing for all ligand bonds to rotate. The center points of the grid box were set to X: -26.299, Y: 12.6039 , and Z: 58.9455 , and the dimensions (in $\AA$ ) were X: 50.3334, Y: 67.2744, and Z: 59.2586. PyMol and BIOVIA Discovery Studio were used to visualize the non-bonding interactions between the docked protein-ligand complexes were further applied to analyze the docking pose. The best conformation was selected based on the lowest docking score (in $\mathrm{kcal} / \mathrm{mol}$ ).

\subsection{ADMET}

ADMET (absorption, distribution, metabolism, excretion, and toxicity) predictions were used, using reliable online servers including SwissADME [52], admetSAR [53], and pKCSM [54] to examine the pharmacokinetic properties. Canonical simplified molecularinput line-entry system (SMILES) structures for the screened phytochemicals were retrieved from the PubChem database and used as inputs for the webservers to generate predictions regarding their drug-likeness properties.

\subsection{Molecular Dynamics Simulation}

Molecular dynamics simulations for the docked complexes were performed to understand the structural variations across the simulation trajectories. The YASARA dynamics software [55] package was used to run the molecular dynamics simulations, in which the AMBER14 force field [56] was employed. A cubic simulation cell was created, and our ligand-protein complexes were incorporated into the simulation's cells. The simulation cell was extended $20 \AA$ more than the protein complex, to move freely. The TIP3P water solvation model was used, and the steepest gradient approaches were used to perform the energy minimization procedure using simulated annealing methods [57]. The simulation environment was neutralized at a temperature of $310 \mathrm{~K}, \mathrm{pH} 7.4$, and $0.9 \% \mathrm{NaCl}$. The longrange electrostatic interactions were calculated using Particle Mesh Ewald's algorithms by setting a cutoff radius of $8 \AA$ [58]. The simulation time was set to 1.25 fs. Each simulation was run for $100 \mathrm{~ns}$, and each trajectory was saved after 100 ps. Finally, simulation snapshots were used to calculate the root-mean-square deviation (RMSD), root-mean-square fluctuation (RMSF), the radius of gyration (Rg), solvent-accessible surface area (SASA), and hydrogen bonds [59-68].

\section{Results}

\subsection{Molecular Docking Analysis}

Based on the most significant negative docking scores, we set the thresholds of $-7.5 \mathrm{kcal} / \mathrm{mol}$ [69]. The top three potential candidates (Figure 1) were selected for further analysis, including epicatechin-3-O-gallate, psi-taraxasterol, and catechin gallate, which had binding affinities of $-8.4,-8.5$, and $-8.8 \mathrm{kcal} / \mathrm{mol}$, respectively.

The epicatechin-3-O-gallate- $\mathrm{M}^{\text {pro }}$ complex formed three conventional hydrogen bonds at His164, His163, and Asn142, one carbon-hydrogen bond at Gln189, and two pi-alkyl bonds at Met165 and Pro168. In contrast, the complex between $\mathrm{M}^{\text {pro }}$ and psi-taraxasterol was stabilized by three alkyl bonds at Met165, Met49, and Cys145, and one pi-alkyl bond at His41 position.

Catechin gallate interacted with $\mathrm{M}^{\text {pro }}$ through four conventional hydrogen bonds at Leu141, His163, Arg188, and Thr190, one carbon-hydrogen bond at Gln189, one pi-pi T-shaped bond at His4, and three pi-alkyl bonds at Met165, Cys145, and Met49 position (Figure 2 and Table 1). 
Table 1. Non-bond interactions between SARS-CoV-2 main protease and the top three (3) compounds.

\begin{tabular}{|c|c|c|c|c|c|}
\hline Compounds & $\begin{array}{l}\text { PubChem } \\
\text { CID }\end{array}$ & $\begin{array}{l}\text { Binding Affinity } \\
\text { (kcal/mol) }\end{array}$ & $\begin{array}{l}\text { Residues in } \\
\text { Contact }\end{array}$ & Interaction Type & Distance in $\AA$ \\
\hline \multirow{6}{*}{$\begin{array}{l}\text { Epicatechin-3-O- } \\
\text { gallate }\end{array}$} & \multirow{6}{*}{65056} & \multirow{6}{*}{-8.4} & HIS164 & Conventional hydrogen bond & 2.51938 \\
\hline & & & HIS163 & Conventional hydrogen bond & 2.28965 \\
\hline & & & ASN142 & Conventional hydrogen bond & 2.57732 \\
\hline & & & GLN189 & Carbon hydrogen bond & 2.19623 \\
\hline & & & MET165 & Pi-alkyl & 5.3972 \\
\hline & & & PRO168 & Pi-alkyl & 5.49119 \\
\hline \multirow{4}{*}{ Psi-taraxasterol } & \multirow{4}{*}{5270605} & \multirow{4}{*}{-8.5} & MET165 & Alkyl & 5.04103 \\
\hline & & & MET49 & Alkyl & 3.86071 \\
\hline & & & CYS145 & Alkyl & 5.38342 \\
\hline & & & HIS41 & Pi-alkyl & 5.35384 \\
\hline \multirow{9}{*}{ Catechin gallate } & \multirow{9}{*}{6419835} & \multirow{9}{*}{-8.8} & LEU141 & Conventional hydrogen bond & 2.05522 \\
\hline & & & HIS163 & Conventional hydrogen bond & 1.92422 \\
\hline & & & ARG188 & Conventional hydrogen bond & 2.46163 \\
\hline & & & THR190 & Conventional hydrogen bond & 2.05509 \\
\hline & & & GLN189 & Carbon hydrogen bond & 2.3535 \\
\hline & & & HIS41 & Pi-Pi T-shaped & 5.22838 \\
\hline & & & MET165 & Pi-alkyl & 4.91554 \\
\hline & & & CYS145 & Pi-alkyl & 5.4117 \\
\hline & & & MET49 & Pi-alkyl & 5.21898 \\
\hline
\end{tabular}

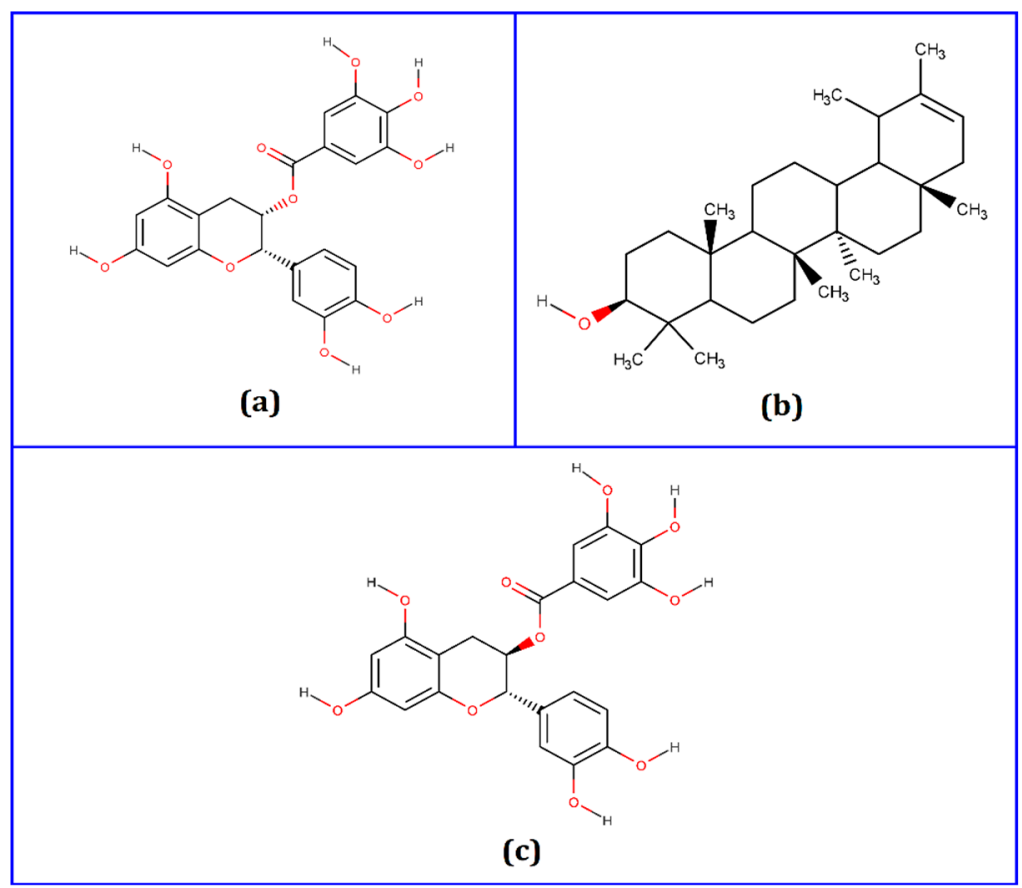

Figure 1. Two-dimensional (2D) chemical structures of (a) epicatechin-3-O-gallate, (b) psi-taraxasterol, and (c) catechin gallate. The structures were drawn using MarvinSketch software. 

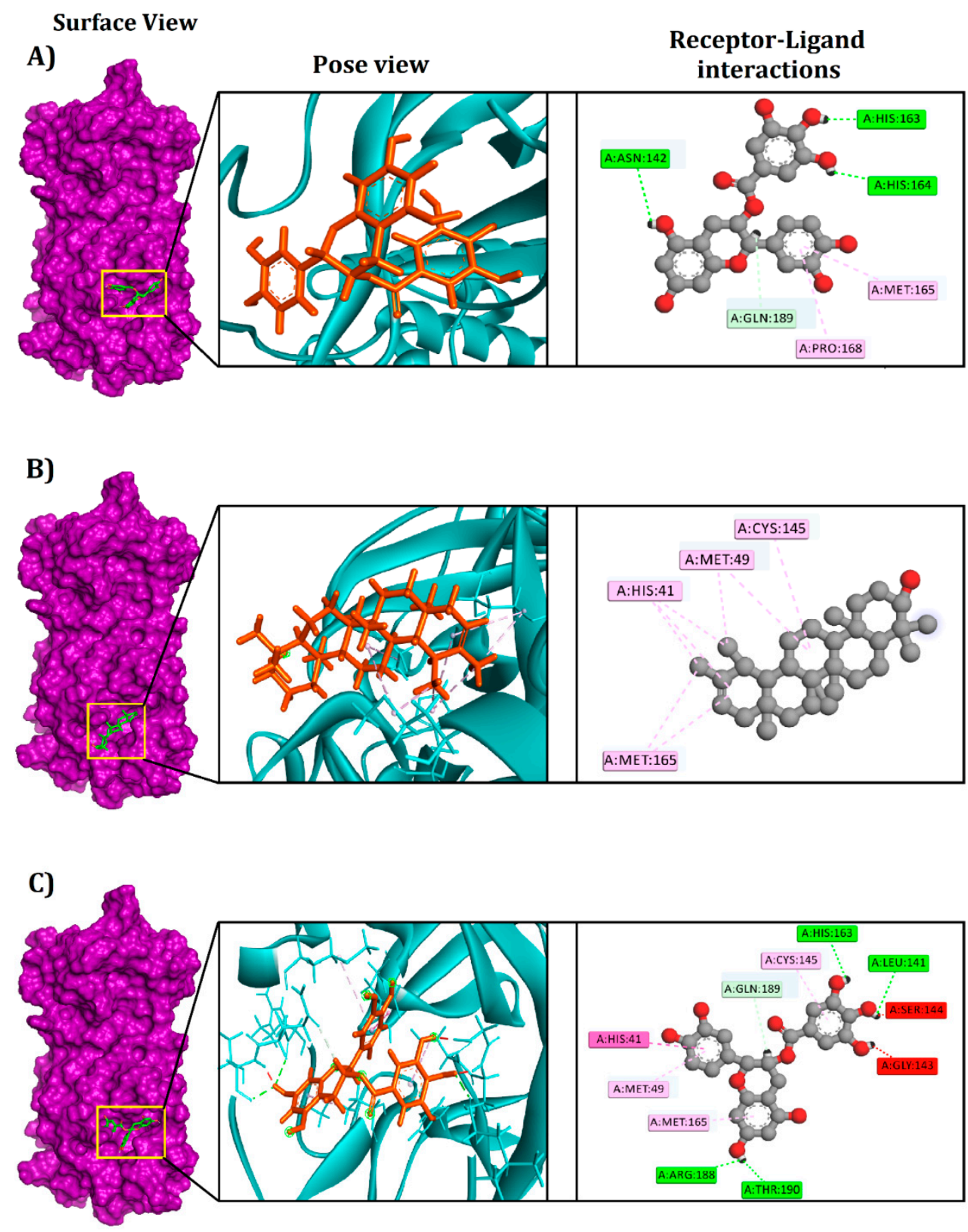

Figure 2. The various binding modes for the selected compounds within the active and catalytic sites of the SARS-CoV-2 main protease. (A) epicatechin-3-O-gallate, (B) psi-taraxasterol, and (C) catechin gallate.

\subsection{ADMET}

To examine each candidate molecule's efficiency and safety characteristics, various properties of the ligands, including toxicity and pharmacokinetics profiles, were evaluated. Additional parameters of the lead molecules, including p-glycoprotein inhibition, central nervous system (CNS) permeability, carcinogenicity, hepatotoxicity, human intestinal absorption, and cytochrome $\mathrm{P}(\mathrm{CYP})$ inhibition, were computationally predicted (Table 2). CNS permeability refers to the ability of a molecule to permeate across the selective, semipermeable border of the blood-brain barrier. CNS permeability greater than -2 (CNS > -2) is considered to indicate the capacity to penetrate the CNS. The psi-taraxasterol had the CNS permeability of about -2.0 (1.992). The lower level of efficacy and toxicity is the main driving force for the failure of the drug candidates in clinical trials. The prime determinant of the drug penetrability of the biological systems depends on how efficiently they are permeable in the central nervous system and cell membranes [70]. The 
top three compounds, including the psi-taraxasterol, had a better probability of crossing the biological barriers in the ADMET study, which defines the better efficacy probability of the compounds. Among the three top candidate compounds, no probability of toxicity or carcinogenicity was observed. The molecular weights (MWs) of these three compounds were $442.4,426.7$, and $442.4 \mathrm{~g} / \mathrm{moL}$ for epicatechin-3-O-gallate, psi-taraxasterol, and catechin gallate, respectively. These MWs were optimal for prime molecule consideration because compounds with higher MWs transgress the Lipinski rule of five. The numbers of hydrogen bond acceptors and donors for these three ligand molecules were also evaluated. The numbers of hydrogen bond donors were reported as 7, 1, and 7, respectively, for epicatechin-3-O-gallate, psi-taraxasterol, and catechin gallate, whereas the numbers of hydrogen bond acceptors were 10,1, and 10. All three ligands were found to maintain the Lipinski rule of five and none were found to cause acute oral toxicity or hepatotoxicity.

Table 2. Pharmacological profiles for the top three potential candidates, which were derived from the SwissADME, admetSAR, and pKCSM webservers.

\begin{tabular}{cccc}
\hline Parameters & Epicatechin-3-O-gallate & Psi-taraxasterol & Catechin gallate \\
\hline Molecular weight & $442.4 \mathrm{~g} / \mathrm{moL}$ & $426.7 \mathrm{~g} / \mathrm{moL}$ & $442.4 \mathrm{~g} / \mathrm{moL}$ \\
H-bond acceptor & 10 & 1 & 10 \\
H-bond donor & 7 & 1 & 7 \\
CNS & -3.743 & -1.992 & -3.743 \\
CYP2D6 substrate & No & No & No \\
CYP3A4 substrate & No & Yes & No \\
CYP1A2 inhibitor & No & No & No \\
CYP2C19 inhibitor & No & No & No \\
CYP2C9 inhibitor & No & No & No \\
CYP2D6 inhibitor & No & No & Non-carcinogenic \\
CYP3A4 inhibitor & No & No \\
Carcinogenicity & Non-carcinogenic & No & No \\
Hepatotoxicity & No & No & +0.9942 \\
P-glycoprotein inhibitor & No & +0.9919 & -0.5000 \\
Human intestinal absorption & +0.9942 & -0.8500 & No \\
Ames mutagenesis & -0.5000 & No & Yes \\
Acute oral toxicity & No & Yes & Nes \\
Lipinski rule of five & & & \\
\hline
\end{tabular}

\subsection{Molecular Dynamics Simulation}

The RMSD of the C-alpha atoms from the simulation trajectories were assessed to understand changes in the protein-ligand complex's stability. Figure 3a shows that the psi-taraxasterol-M ${ }^{\text {pro }}$ complex presented an initial increase in its RMSD profile between 0 and $40 \mathrm{~ns}$ due to a higher degree of instability in the protein-ligand complex. The RMSD profile decreased drastically at $40 \mathrm{~ns}$ before increasing again at $50 \mathrm{~ns}$. The RMSD descriptors from this complex indicated the maintenance of stability after $50 \mathrm{~ns}$, with few fluctuations observed. In contrast, the other two complexes, formed between $\mathrm{M}^{\mathrm{pro}}$ and epicatechin or catechin gallate, both achieved stable RMSD profiles after $10 \mathrm{~ns}$ in the simulations. Although the psi-taraxasterol complex exhibited a higher degree of deviation compared with epicatechin-3-O-gallate and catechin gallate, psi-taraxasterol did not exceed its RMSD profile by more than $2.5 \AA$. The average RMSD of apo, epicatechin-3-O-gallate, psi-tarasterol, and catechin gallate were $1.591,1.151,1.337,1.111 \AA$, respectively.

Moreover, the SASAs of the simulation complexes were analyzed to determine changes in the protein volume. A larger SASA profile indicates the expansion of the protein surface area, whereas a lower SASA profile denotes the truncation of the protein-ligand complex. The catechin gallate- $\mathrm{M}^{\text {pro }}$ complex displayed an expanded surface area after $20 \mathrm{~ns}$ in the simulation, which was stably maintained within the simulation environment. A lower degree of change in the SASA profile was observed for this compound compared with the other two compounds, but the deviations were not large. The psi-taraxasterol and 
epicatechin-3-O-gallate complexes had similar SASA profiles starting at the beginning of the simulations, and each compound displayed slightly expanded surface areas at $60 \mathrm{~ns}$ (Figure 3b). The average of the SASA from the apo, epicatechin-3-O-gallate, psi-tarasterol, and catechin gallate were $14163.56,14013.39,14097.55$, and $14004.83 \AA^{2}$, respectively.

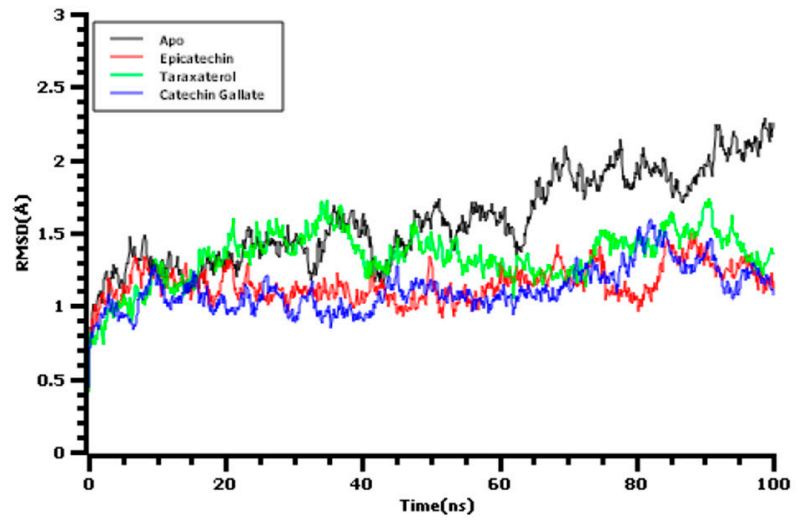

(a)

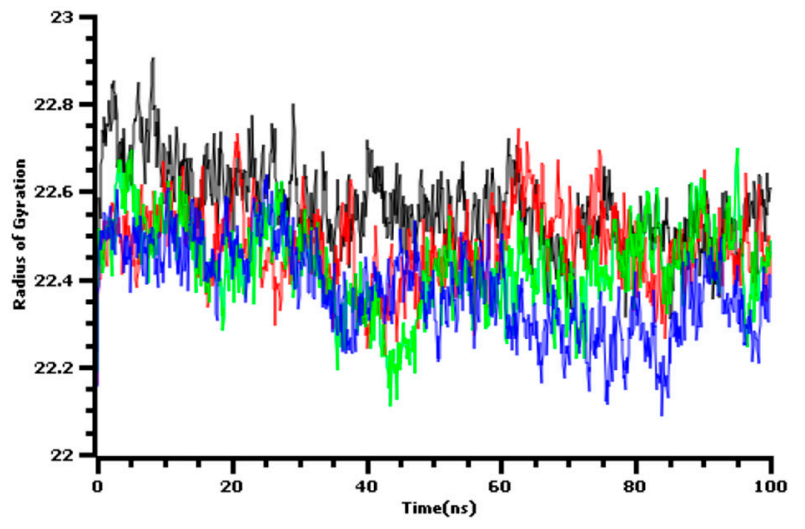

(c)

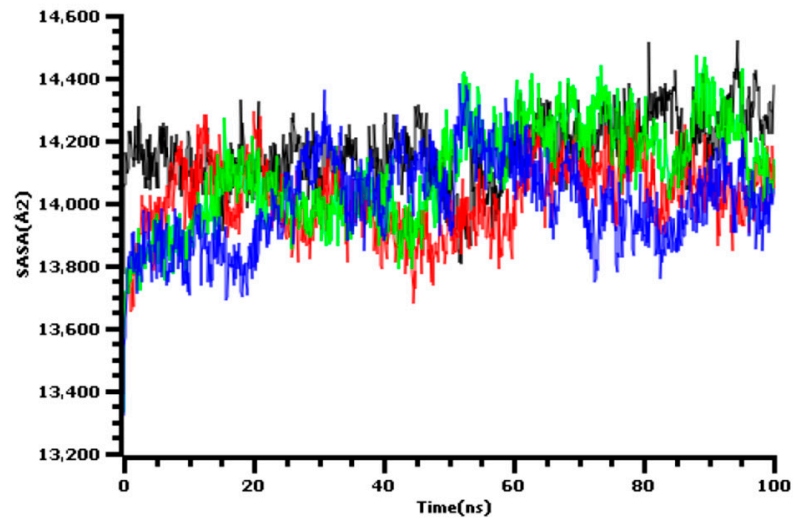

(b)

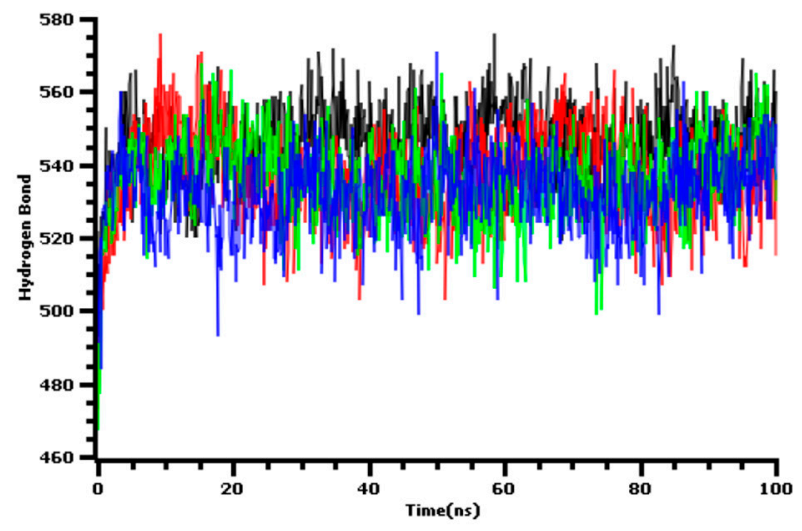

(d)

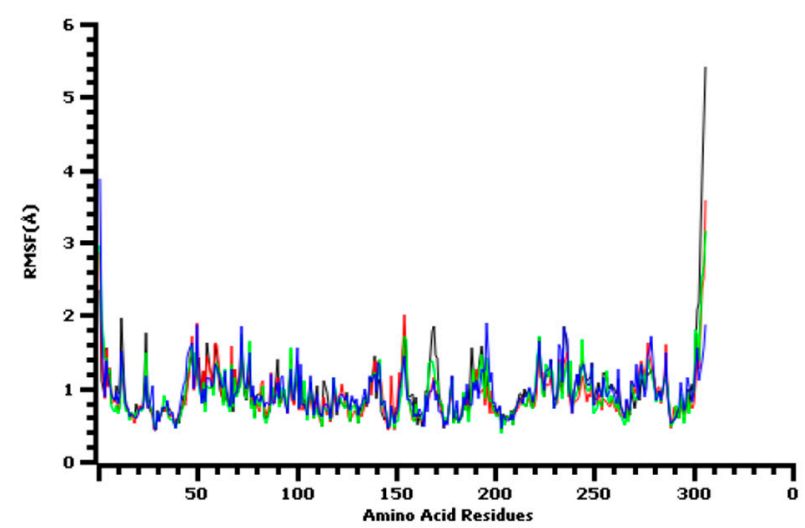

(e)

Figure 3. Time series analyses for all three simulated systems. (a) RMSD analysis for the alpha carbon atoms, (b) protein volume with expansion analysis, (c) degree of rigidity and compactness analysis, (d) hydrogen bond analysis, and (e) flexibility analysis of amino acid residues. 
The $\mathrm{Rg}$ values from the simulation trajectories were examined to understand the labile nature of the drug-protein complexes. Figure $3 \mathrm{c}$ shows that the $\mathrm{Rg}$ values for the three complexes decreased from 0 to $30 \mathrm{~ns}$ during the simulation. After $30 \mathrm{~ns}$, all three complexes showed similar, straight-line Rg profiles for the remainder of the simulation. A low $\mathrm{Rg}$ profile correlates with a less labile nature and the increased rigidity of the simulated complexes. The average $\mathrm{Rg}$ of the apo, epicatechin-3-O-gallate, psi-tarasterol, and catechin gallate were $22.567,22.447,22.429$, and $22.378 \AA$, respectively.

The formation of hydrogen bonds in the simulation system defines the integrity and stable nature of each protein-ligand complex. Figure $3 \mathrm{~d}$ demonstrates that all three complexes formed stable hydrogen bonds throughout the $100 \mathrm{~ns}$ molecular dynamics simulation trajectories. The average hydrogen bond between solute and solvent systems of the apo, epicatechin-3-O-gallate, psi-tarasterol, and catechin gallate were 545.977, 536.373, 535.982, and 532.281, respectively.

In addition, the RMSF profiles of all three compounds were analyzed to understand changes in the amino acid residues involved in the hydrogen bond formation.

Figure 3e indicates that most of the amino acid residues had low RMSF values for all three complexes, except Ser1, Leu50, Asn72, Tyr154, Thr196, Ser301, Val303, Thr304, Phe305, and Gln306.

The binding interactions of the top three docked complexes were further evaluated after $100 \mathrm{~ns}$ in the simulation to understand their changes after the simulation study (Table 3). Epicatechin-3-O-gallate formed had five hydrogen bonds with $\mathrm{M}^{\mathrm{pro}}$, at Ser144, His163, Phe140, Cys145, and His41, and three pi-alkyl bonds were observed for Leu141, Met49, and Cys165. Psi-taraxasterol formed three hydrogen bonds with $\mathrm{M}^{\mathrm{pro}}$ at Cys145, Met165, and Met49. This complex also formed a pi-alkyl bond at His41. Catechin gallate exhibited a higher number of hydrogen bonds after the 100-ns simulation, forming seven hydrogen bonds at Asn142, Leu141, Glu166, Met49, Val186, Arg188, and Met165 and two pi-alkyl bonds at Cys145 and His41.

Table 3. The binding interactions of the docked complex after $100 \mathrm{~ns}$ in the molecular dynamics simulation study. $\mathrm{H}$ indicates hydrogen and PI indicates pi-alkyl bond.

\begin{tabular}{cccc}
\hline Complex & Residues & Interactions & Distance \\
\hline \multirow{4}{*}{ Epicatechin-3-O-gallate } & Ser144 & $\mathrm{H}$ & 1.78 \\
& His163 & $\mathrm{H}$ & 2.73 \\
& Phe140 & $\mathrm{H}$ & 1.96 \\
& Cys145 & $\mathrm{H}$ & 2.50 \\
& His41 & $\mathrm{H}$ & 2.89 \\
& Leu141 & PA & 4.21 \\
& Met49 & PA & 5.18 \\
& Cys165 & PA & 5.23 \\
\hline \multirow{3}{*}{ Psi-taraxasterol } & Cys145 & H & 1.23 \\
& Met165 & H & 2.21 \\
& Met49 & H & 2.73 \\
& His41 & PA & 4.33 \\
\hline & Asn142 & H & 1.81 \\
& Leu141 & H & 2.24 \\
& Glu166 & H & 1.50 \\
& Met49 & H & 3.03 \\
& Val186 & H & 2.92 \\
& Arg188 & H & 1.83 \\
& Met165 & H & 2.39 \\
& Cys145 & PA & 5.21 \\
& His41 & PA & 5.53 \\
\hline
\end{tabular}




\section{Discussion}

The SARS-CoV-2 virus causes a fatal infection of the respiratory tract, and the viral genome features 1516 nucleotide-level variations based on genome-wide annotations. Currently, no highly effective therapeutic treatments are widely available, and combating the outbreak has become a global crisis [71,72]. Computer-aided drug design can be used as an efficient method for recognizing reliable drug candidates that can be repurposed for use against SARS-CoV-2 because detailed analyses of receptor-ligand interactions and $3 \mathrm{D}$ structures of the main viral proteins have become available. Although no efficient inhibitor for the targeted SARS-CoV-2 protease has yet been implemented in any clinical development programs, non-covalent protease inhibitors have potential advantages for combating viral infections [30,72-74].

The active sites of $\mathrm{M}^{\mathrm{pro}}$ are largely conserved across various coronaviruses, and $\mathrm{M}^{\text {pro }}$ is functionally important for viral replication and the viral life cycle; therefore, the inhibition of $\mathrm{M}^{\text {pro }}$ represents a feasible strategy for the generation of plausible antiviral drugs designed to suppress the ongoing SARS-CoV-2 impacts [75-77].

According to the 3D structure of SARS-CoV-2 $\mathrm{M}^{\text {pro }}$, the active $\mathrm{M}^{\text {pro }}$ homodimer comprises two protomers, constituting three domains. Amino acid residues 8-101 constitute Domain I, amino acid residues 102-184 constitute Domain II, and amino acid residues 201-306 constitute Domain III. The substrate-binding zone, which is found in the cleft between Domain I and Domain II, resembles the SARS-CoV-2 active site and consists of a conserved and noncanonical His41 and Cys145 catalytic dyad. His41 is a well-known conserved residue across coronaviruses [73,76].

Additionally, S1 and S2 represent densely buried subsites, with S1 comprised of Phe140, Glu166, Gly143, Cys145, Glu166, and His163 and S2 comprised of His41, Thr25, and Cys145. Moreover, the shallow S3-S5 subsites are comprised of Gln189, Met49, Glu166, Met165, Glu166, and His41 residues [30,75-81].

The virtual screening technique represents a feasible screening process that can be used to identify a plausible inhibitor from among an expansive array of phytochemicals. Molecular docking allows for the evaluation of interaction binding affinities between the target protein and a diverse array of ligands. Thus, the application of the molecular docking approach allows for the rapid recognition of potentially effective inhibitors through the assessment of the binding energies of a massive quantity of candidate ligands within a short period of time, which is a major advantage of virtual screening [82-85].

Based on our computational screening results, three potent inhibitors targeting the SARS-CoV-2 $\mathrm{M}^{\text {pro }}$ were identified that exhibit significant binding affinities and interaction with the active groove of the target protein, which is vital for targeted $\mathrm{M}^{\text {pro }}$ inhibition. Our first compound, epicatechin-3-O-gallate, was found to have anti-melanogenic effects [86], acts as a chemopreventative for multistage carcinogenesis [87], plays a crucial role in Alzheimer disease through the inhibition of a $\beta$ aggerates formation [88], and inhibits cell invasion and protease activity [89] within the human body. Furthermore, it can chelate $\mathrm{Zn}^{2+}$ and $\mathrm{Cu}^{2+}$ to lessen reactive oxygen species production, which can alleviate neurotoxicity induced by $\mathrm{Cu}^{2+}$ - and $\mathrm{Zn}^{2+}-\mathrm{A} \beta 40$ [88]. The availability of the antimetastatic effect, the suppression of tumor growth in the A549 cells [89], along with the competency to pass through the blood-brain impediment [88], has dispensed therapeutic impacts of epicatechin-3-Ogallate as an anti-invasion and anti-cancer agent [89]. This phytochemical formed multiple non-covalent bonds with $\mathrm{M}^{\text {pro }}$, including five interactions that were observed in the active site of $\mathrm{M}^{\mathrm{pro}}$ : His164 (hydrogen), Asn142 (hydrogen), Gln189 (hydrogen), Met165 (pi-alkyl), and Pro168 (pi-alkyl). Post-molecular dynamics interactions also confirmed several interactions with active site residues with precise rigidity, which may be responsible for the inhibition [90].

The phytochemical psi-taraxasterol has been associated with multiple functions in the cell and enzymatic assays, including anti-edematous activity [91], inflammation, and the anti-inflammatory response [92]. This compound formed numerous non-bonded interactions at the active site (Met165, Met49, Cys145, His41) of Mpro, both before and after the 
molecular dynamics simulation. Although this compound had a relatively higher distance in docking interactions at $0 \mathrm{~ns}$, the interactions remained stable across the simulation trajectories. Moreover, their interactions were driven by alkyl and pi-alkyl interactions, but at the last simulation trajectories, they were seen to form more hydrogen bond and hydrophobic interactions at the active sites by relatively lower distance. These non-covalent interactions by engaging the $\pi$ systems are crucial for the ligand-protein interactions [93]. Therefore, the interacting residues of these complexes seem to bind tightly after specific periods of simulation time, which provides crucial insights into the rigid binding of this complex. Therefore, this compound may undergo some degree of conformational changes to the docking snapshots, which ultimately led to the tight bindings after 100-ns times.

In addition, catechin gallate has shown significant effect as an antimalarial agent [94] and in the lipogenesis pathway [95] and demonstrated potential and much heftier antiproliferative and anti-inflammatory actions in pancreatic tumor cells [96]. This phytochemical can suppress the activity of HIV-1 integrase. Moreover, it may lessen HIV-1 integrase activity by shattering its influence with virus DNA [97]. Besides, catechin gallate can inhibit consumption of methyl glucose by adipocytes [98]. The catechin gallate-Mpro complex interacted at residues within the active cavity, including Leu141, Thr190, Gln189, His41, Met165, Cys145, Met49, and Glu166, both before and after the molecular dynamics simulation.

The virtual screening and molecular docking study were also conducted against the main protease of SARS-CoV-2 by taking FDA-approved drugs from the ZINC database where they have found binding energy ranges from -7.8 to $-6.839 \mathrm{kcal} / \mathrm{mol}$ [99], whereas we have found epicatechin-3-O-gallate, psi-taraxasterol, and catechin gallate having binding affinities of $-8.4,-8.5$, and $-8.8 \mathrm{kcal} / \mathrm{mol}$. Additionally, multiple studies regarding the virtual screening and molecular docking were conducted by targeting the main protease of SARS-CoV-2 where several interactions at the active points Thr26, Leu41, Cys145, Pro168, Asn142, His164, Met49, Phe140, Met165, Glu166, Gln189, and Thr190 [99-103] were observed, which is similar to our findings.

The molecular dynamics simulation study was performed for the best-studied complexes to support the molecular docking assessment, and multiple descriptors from the simulation trajectories were assessed to identify binding rigidity. The RMSDs of the docked complexes were all below $2.5 \AA$ for the C-alpha atom, although psi-taraxasterol had comparatively higher flexibility. The RMSF of the amino acid residues confirmed the less flexible area in Domain 2, with slightly more flexibility observed for Domains 1 and 3 of Mpro. The protein volume for the three docked complexes did not show any alterations in the SASA profiles during the simulation trajectories for all three complexes, which had low degrees of variation. The quantitative assessment of hydrogen bond patterns and the Rg profiles of these three complexes were similar to other descriptors of simulations.

Moreover, a superimposition of the structures before and after molecular dynamics was performed (Figure 4) to determine changes in the binding cavity. The top screened complexes, including epicatechin-3-O-gallate, psi-taraxasterol, and catechin gallate, had RMSD values of $1.25,1.78$, and $1.65 \AA$, respectively. We also took snapshots from different simulation trajectories, at 25,50,75, and $100 \mathrm{~ns}$, for the three top complexes, and no radical alterations were observed for all three complexes (Figures 5-7). 


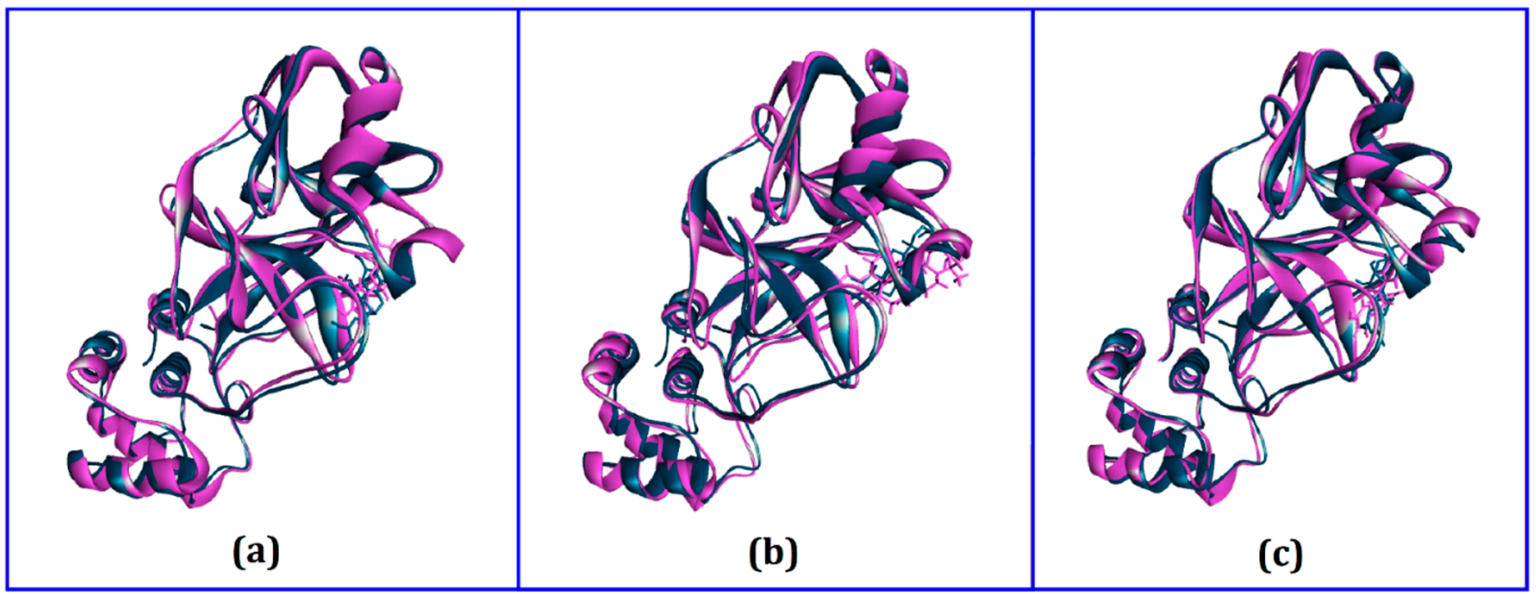

Figure 4. Superimpositions of the drug-protein complex before and after molecular dynamics. Purple color indicates the baseline structure and dark blue indicates the structure after molecular dynamics. (a) Epicatechin-3-O-gallate, (b) Psitaraxasterol, and (c) Catechin gallate.

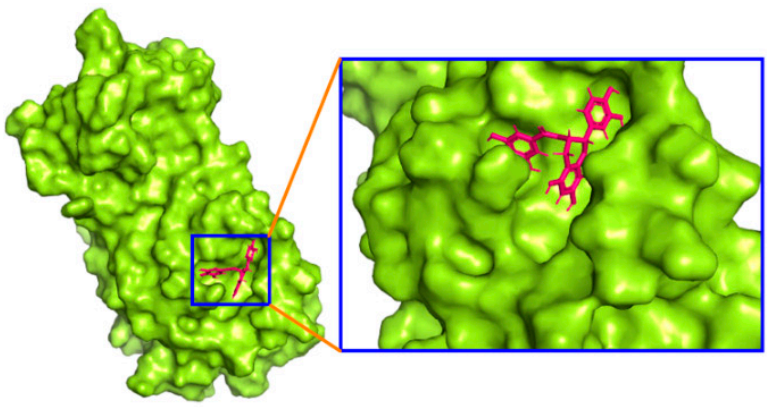

$25 \mathrm{~ns}$

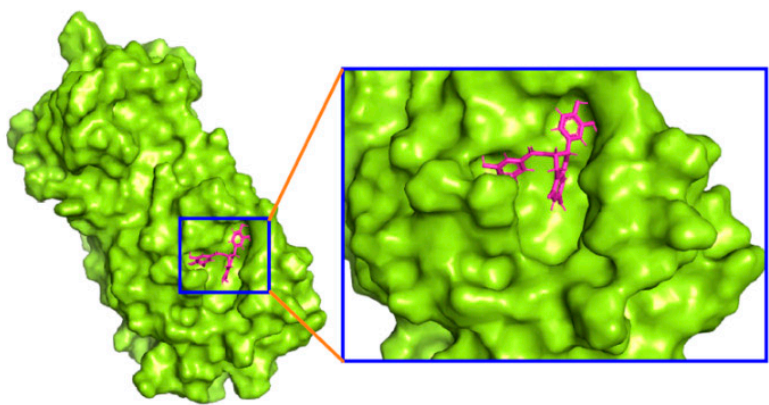

$75 \mathrm{~ns}$

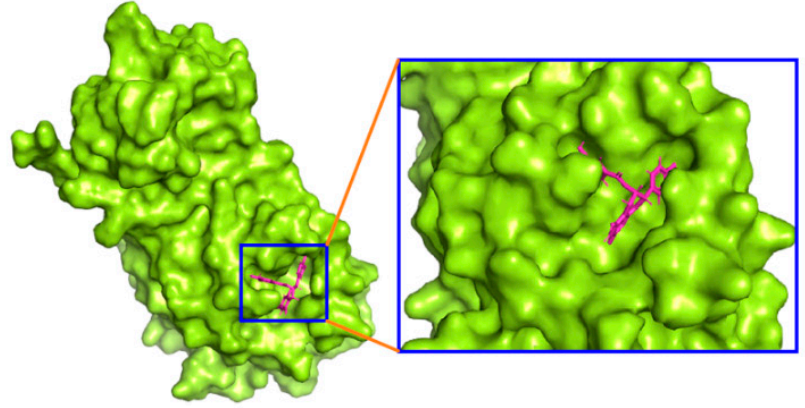

$50 \mathrm{~ns}$

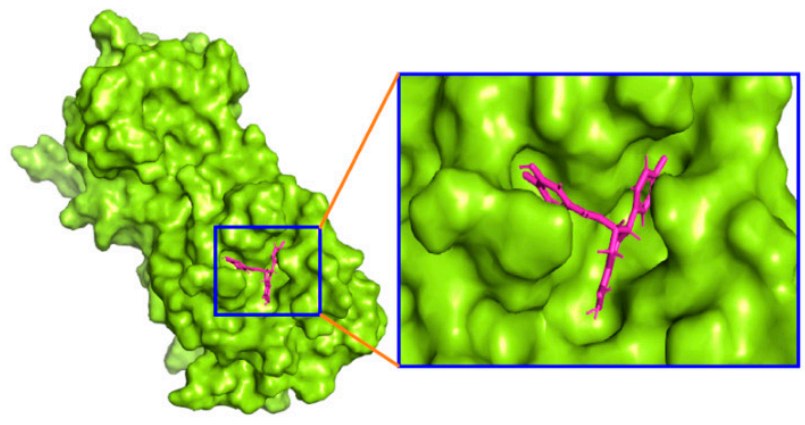

$100 \mathrm{~ns}$

Figure 5. Surface views for the docked complex in the molecular dynamics simulation. The snapshots were taken at 25, 50, 75, and $100 \mathrm{~ns}$, respectively, for (+)-epicatechin-3-O-gallate and the Mpro complex. 

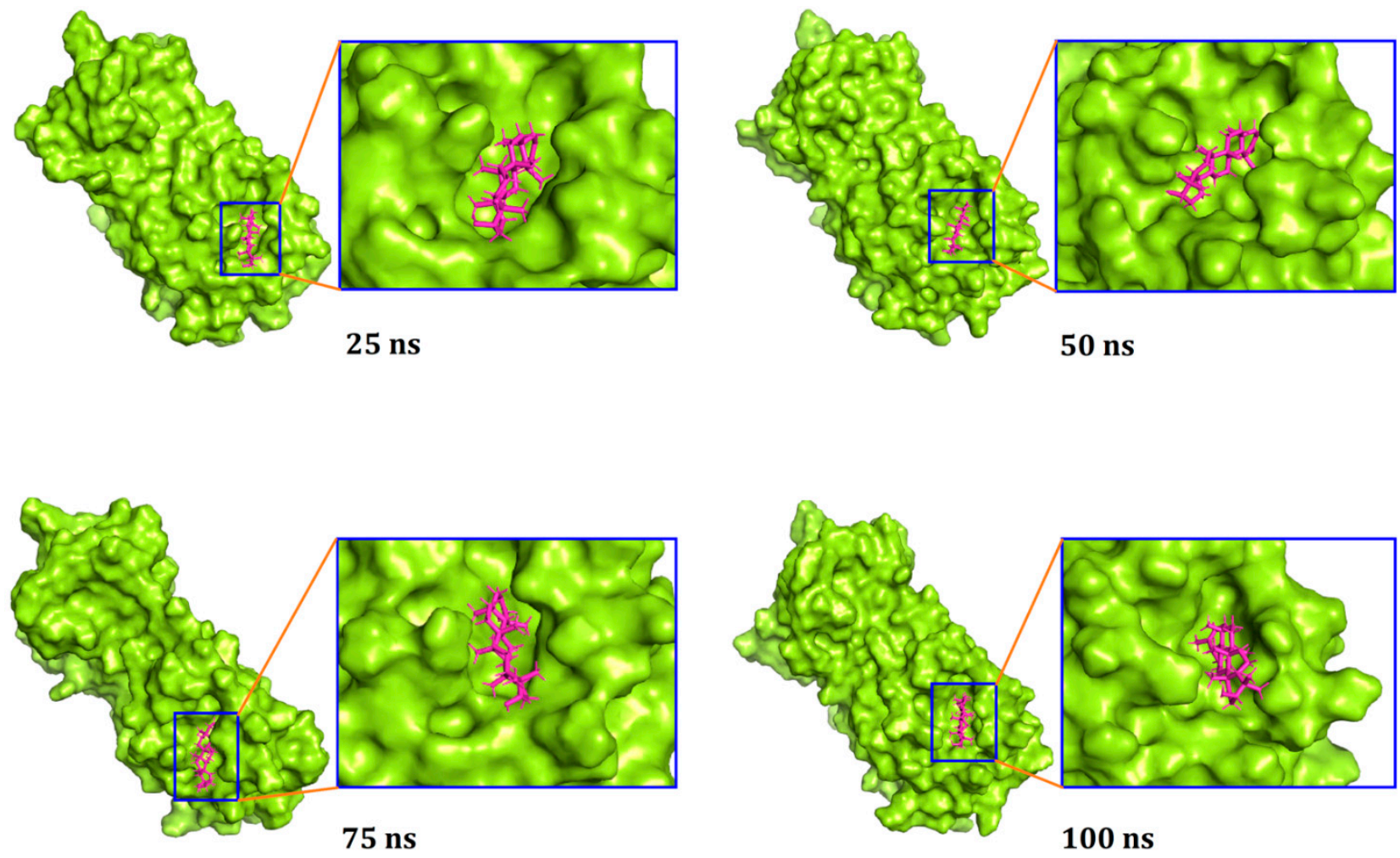

Figure 6. The surface view and the binding pockets between psi-taraxasterol and $\mathrm{M}^{\text {pro }}$ complex, with snapshots at 25,50 , 75 , and $100 \mathrm{ns.}$
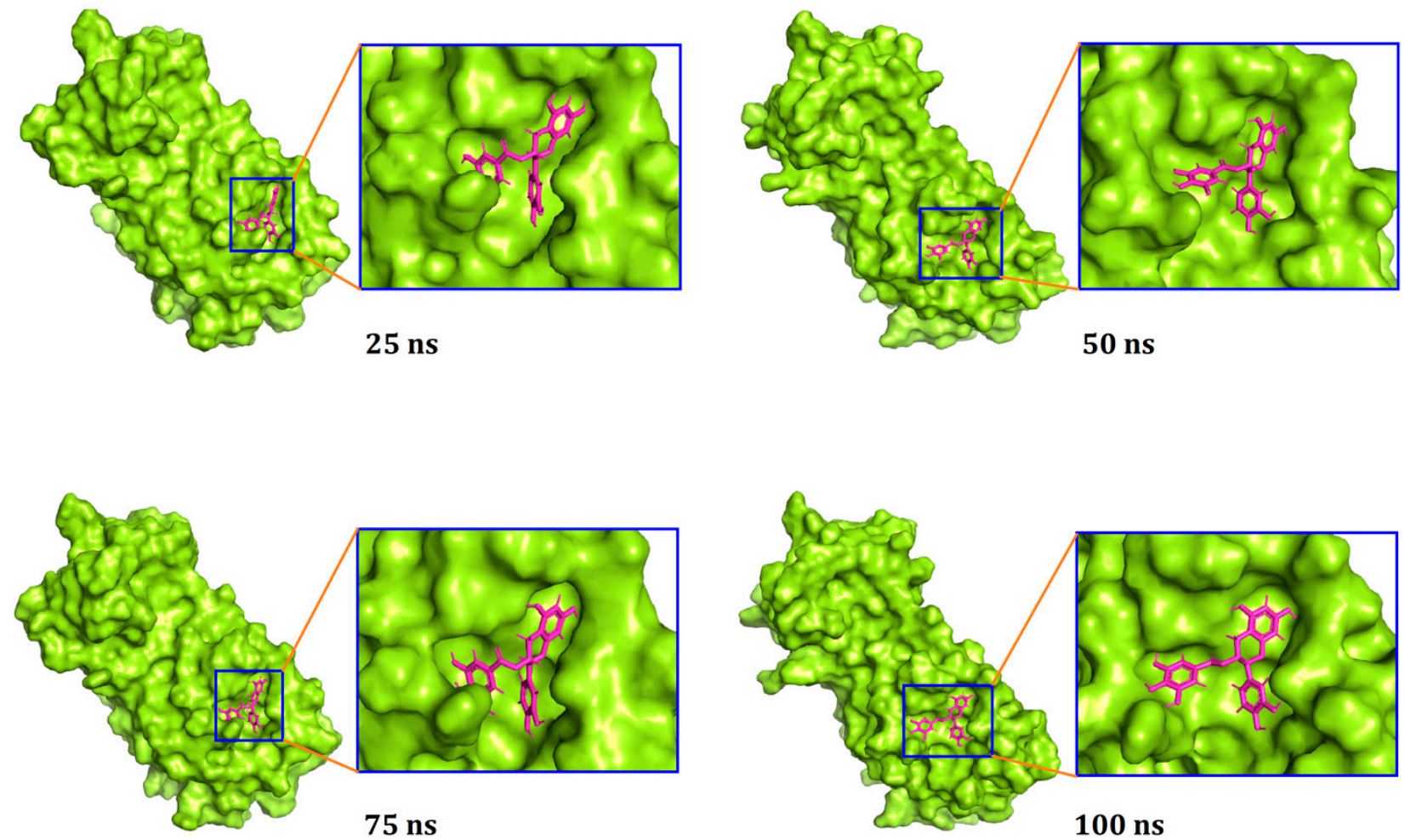

Figure 7. The surface view of the docked (-)-catechin gallate and Mpro complex, with snapshots at 25, 50, 75, and 100 ns. 


\section{Conclusions}

In this workflow, we first short-listed 1672 plant-based phytochemicals through deep literature mining. The compounds were screened against the SARS-CoV-2 $\mathrm{M}^{\text {pro }}$ to identify potent inhibitors that might be able to interfere with the catalytic function of $\mathrm{M}^{\mathrm{pro}}$. The virtual screening and molecular docking studies identified three potent inhibitors: epicatechin-3-O-gallate, psi-taraxasterol, and catechin gallate from several large, compound data sets. Furthermore, the molecular simulation study of the docked complexes supported the stable nature and rigid conformations formed by the docked complexes, as assessed by the simulation trajectories and based on multiple descriptor analyses. The binding interactions were confirmed at several active sites, including His41, Cys145, Met49, and Glu166, and their stiffness was confirmed after molecular dynamics. This combinatorial screening was solely based on computational pipelines; therefore, additional in vitro assays must be performed to confirm the precise targeting of these compounds against SARS-CoV-2.

Supplementary Materials: The following are available online: https:/ /www.mdpi.com/article/10.3 390/biology10070589/s1. Table S1: A total of 1672 compounds used in the virtual screening from 32 plants. Table S2: A total of 1672 compounds used in the virtual screening from 10 plants. Table S3: A total of 1672 compounds used in the virtual screening from 14 plants.

Author Contributions: Conceptualization, S.M., S.B., G.K.P. and M.A.S.; methodology, S.M., S.B., G.K.P., M.A.M., M.M.P., S.A., M.R.H., S.Z., M.S.U., K.D. and T.B.E.; software, S.M., S.B., G.K.P. and T.B.E.; validation, M.R.H., S.Z., M.S.U., T.B.E., M.A.S. and J.S.-G.; formal analysis, M.R.H., S.Z., M.S.U., K.D., T.B.E., M.A.S. and J.S.-G.; investigation, S.M., S.B., G.K.P. and M.A.M.; resources, S.M., S.B., T.B.E., M.A.S., K.D. and J.S.-G.; data curation, S.M., S.B., G.K.P., M.A.M., M.M.P., S.A., M.R.H., S.Z. and M.S.U.; writing—original draft preparation, S.M., S.B. and G.K.P.; writing-review and editing, K.D., T.B.E., M.A.S. and J.S.-G.; visualization, K.D., T.B.E., M.A.S. and J.S.-G.; supervision, M.A.S.; T.B.E. and J.S.-G.; project administration, M.A.S.; T.B.E. and J.S.-G.; funding acquisition, J.S.-G. All authors have read and agreed to the published version of the manuscript.

Funding: This research received no external funding.

Institutional Review Board Statement: Not applicable.

Informed Consent Statement: Not applicable.

Data Availability Statement: Available data are presented in the manuscript.

Conflicts of Interest: The authors declare no conflict of interest.

\section{References}

1. Akhmetzhanov, A.; Mizumoto, K.; Jung, S.; Linton, N.; Omori, R.; Nishiura, H. Estimation of the actual incidence of coronavirus disease (COVID-19) in emergent hotspots: The example of Hokkaido, Japan during February-March 2020. J. Clin. Med. 2020, 10, 2392. [CrossRef]

2. Hui, D.S.; Azhar, E.I.; Madani, T.A.; Ntoumi, F.; Kock, R.; Dar, O.; Ippolito, G.; Mchugh, T.D.; Memish, Z.A.; Drosten, C.; et al. The continuing 2019-nCoV epidemic threat of novel coronaviruses to global health-The latest 2019 novel coronavirus outbreak in Wuhan, China. Int. J. Infect. Dis. 2020, 91, 264-266. [CrossRef]

3. Huang, C.; Wang, Y.; Li, X.; Ren, L.; Zhao, J.; Hu, Y.; Zhang, L.; Fan, G.; Xu, J.; Gu, X.; et al. Clinical features of patients infected with 2019 novel coronavirus in Wuhan, China. Lancet 2020, 395, 497-506. [CrossRef]

4. Kandimalla, R.; John, A.; Abburi, C.; Vallamkondu, J.; Reddy, P.H. Current Status of Multiple Drug Molecules, and Vaccines: An Update in SARS-CoV-2 Therapeutics. Mol. Neurobiol. 2020, 57, 4106-4116. [CrossRef]

5. Bhatti, J.S.; Bhatti, G.K.; Khullar, N.; Reddy, A.P.; Reddy, P.H. Therapeutic Strategies in the Development of Anti-viral Drugs and Vaccines Against SARS-CoV-2 Infection. Mol. Neurobiol. 2020, 57, 4856-4877. [CrossRef] [PubMed]

6. Li, L.; Guo, P.; Zhang, X.; Yu, Z.; Zhang, W.; Sun, H. SARS-CoV-2 vaccine candidates in rapid development. Hum. Vaccines Immunother. 2020, 17, 1-10. [CrossRef]

7. Dutta, M.; Nezam, M.; Chowdhury, S.; Rakib, A.; Paul, A.; Sami, S.A.; Uddin, M.Z.; Rana, M.S.; Hossain, S.; Effendi, Y.; et al. Appraisals of the Bangladeshi Medicinal Plant Calotropis gigantea Used by Folk Medicine Practitioners in the Management of COVID-19: A Biochemical and Computational Approach. Front. Mol. Biosci. 2021, 8, 625391. [CrossRef] [PubMed]

8. Qing, H.; Li, Z.; Yang, Z.; Shi, M.; Huang, Z.; Song, J.; Song, Z. The possibility of COVID-19 transmission from eye to nose. Acta Ophthalmol. 2020, 98, e388. [CrossRef] 
9. Huynh, T.; Wang, H.; Luan, B. In Silico Exploration of the Molecular Mechanism of Clinically Oriented Drugs for Possibly Inhibiting SARS-CoV-2's Main Protease. J. Phys. Chem. Lett. 2020, 11, 4413-4420. [CrossRef] [PubMed]

10. Brian, D.A.; Baric, R.S. Coronavirus genome structure and replication. Curr. Top. Microbiol. Immunol. 2005, 287, 1-30. [CrossRef]

11. Shyr, Z.A.; Gorshkov, K.; Chen, C.Z.; Zheng, W. Drug discovery strategies for sars-cov-2. J. Pharmacol. Exp. Ther. 2020, 375, 127-138. [CrossRef] [PubMed]

12. Lin, C.H.; Yang, C.Y.; Wang, M.; Ou, S.C.; Lo, C.Y.; Tsai, T.L.; Wu, H.Y. Effects of Coronavirus Persistence on the Genome Structure and Subsequent Gene Expression, Pathogenicity and Adaptation Capability. Cells 2020, 9, 2322. [CrossRef] [PubMed]

13. Liu, Y.C.; Kuo, R.L.; Shih, S.R. COVID-19: The first documented coronavirus pandemic in history. Biomed. J. 2020, 43, 2-6. [CrossRef]

14. Ullrich, S.; Nitsche, C. The SARS-CoV-2 main protease as drug target. Bioorg. Med. Chem. Lett. 2020, 30, 127377. [CrossRef]

15. Hadda, T.B.; Berredjem, M.; Almalki, F.A.; Rastija, V.; Bader, A.; Jamalis, J.; Emran, T.B.; Abu-Iznei, T.; Esharkawy, E.; Rodriguez, L.C.; et al. How to face COVID-19: Proposed treatments based on Remdesivir and Hydroxychloroquin in presence of zinc-sulfate and POM theory. J. Biomol. Struct. Dyn. 2021, 2021, 1-14. [CrossRef]

16. Chen, Y.; Liu, Q.; Guo, D. Emerging coronaviruses: Genome structure, replication, and pathogenesis. J. Med. Virol. 2020, 92, 418-423. [CrossRef]

17. Li, F. Structure, Function, and Evolution of Coronavirus Spike Proteins. Annu. Rev. Virol. 2016, 3, 237-261. [CrossRef] [PubMed]

18. Naqvi, A.A.T.; Fatima, K.; Mohammad, T.; Fatima, U.; Singh, I.K.; Singh, A.; Atif, S.M.; Hariprasad, G.; Hasan, G.M.; Hassan, M.I. Insights into SARS-CoV-2 genome, structure, evolution, pathogenesis and therapies: Structural genomics approach. Biochim. Biophys. Acta Mol. Basis Dis. 2020, 1866, 165878. [CrossRef]

19. Ceraolo, C.; Giorgi, F.M. Genomic variance of the 2019-nCoV coronavirus. J. Med. Virol. 2020, 92, 522-528. [CrossRef]

20. Zhou, P.; Yang, X.L.; Wang, X.G.; Hu, B.; Zhang, L.; Zhang, W.; Si, H.R.; Zhu, Y.; Li, B.; Huang, C.L.; et al. A pneumonia outbreak associated with a new coronavirus of probable bat origin. Nature 2020, 579, 270-273. [CrossRef]

21. Zhang, T.; Wu, Q.; Zhang, Z. Probable Pangolin Origin of SARS-CoV-2 Associated with the COVID-19 Outbreak. Curr. Biol. 2020, 30, 1346-1351.e2. [CrossRef]

22. Obaidullah, A.J.; Alanazi, M.A.; Alsaif, N.A.; Albassam, H.; Almehizia, A.A.; Alqahtani, A.A.; Mahmud, S.; Sami, S.A.; Emran, T.B. Immunoinformatics-guided design of multi-epitope vaccine from structural proteins of severe acute respiratory syndromecoronavirus-2. RSC Adv. 2021, 11, 18103-18121. [CrossRef]

23. Boopathi, S.; Poma, A.B.; Kolandaivel, P. Novel 2019 Coronavirus Structure, Mechanism of Action, Antiviral drug promises and rule out against its treatment. J. Biomol. Struct. Dyn. 2020, 39, 1-14. [CrossRef] [PubMed]

24. Liu, X.; Wang, X.J. Potential inhibitors against 2019-nCoV coronavirus M protease from clinically approved medicines. J. Genet. Genomics 2020, 47, 119-121. [CrossRef]

25. Ngo, S.T.; Quynh Anh Pham, N.; Thi Le, L.; Pham, D.H.; Vu, V.V. Computational Determination of Potential Inhibitors of SARS-CoV-2 Main Protease. J. Chem. Inf. Model. 2020, 60, 5771-5780. [CrossRef]

26. Fauquet, C.M.; Fargette, D. International Committee on Taxonomy of Viruses and the 3,142 unassigned species. Virol. J. 2005, 2, 1-10. [CrossRef]

27. Zhang, L.; Lin, D.; Sun, X.; Curth, U.; Drosten, C.; Sauerhering, L.; Becker, S.; Rox, K.; Hilgenfeld, R. Crystal structure of SARS-CoV-2 main protease provides a basis for design of improved a-ketoamide inhibitors. Science 2020, 368, 409-412. [CrossRef]

28. Havranek, B.; Islam, S.M. An in silico approach for identification of novel inhibitors as potential therapeutics targeting COVID-19 main protease. J. Biomol. Struct. Dyn. 2020, 2020, 1-12. [CrossRef]

29. Mahmud, S.; Paul, G.K.; Biswas, S.; Afrose, S.; Mita, M.A.; Hasan, M.R.; Shimu, M.S.S.; Hossain, A.; Promi, M.; Ema, F.K.; et al. Prospective role of peptide-based antiviral therapy against the main protease of SARS-CoV-2. Front. Mol. Biosci. 2021, 8, 628585. [CrossRef] [PubMed]

30. Anand, K.; Ziebuhr, J.; Wadhwani, P.; Mesters, J.R.; Hilgenfeld, R. (3CL pro) Structure: Basis for Design of Anti-SARS Drugs. Science 2003, 300, 1763-1767. [CrossRef]

31. Das, S.; Sarmah, S.; Lyndem, S.; Singha Roy, A. An investigation into the identification of potential inhibitors of SARS-CoV-2 main protease using molecular docking study. J. Biomol. Struct. Dyn. 2020, 39, 1-11. [CrossRef]

32. Mahmud, S.; Paul, G.K.; Afroze, M.; Islam, S.; Gupt, S.B.R.; Razu, M.H.; Biswas, S.; Zaman, S.; Uddin, M.S.; Khan, M.; et al. Efficacy of Phytochemicals Derived from Avicennia officinalis for the Management of COVID-19: A Combined In Silico and Biochemical Study. Molecules 2021, 28, 2210. [CrossRef]

33. Ben-Shabat, S.; Yarmolinsky, L.; Porat, D.; Dahan, A. Antiviral effect of phytochemicals from medicinal plants: Applications and drug delivery strategies. Drug Deliv. Transl. Res. 2020, 10, 354-367. [CrossRef] [PubMed]

34. Attia, Y.A.; Alagawany, M.M.; Farag, M.R.; Alkhatib, F.M.; Khafaga, A.F.; Abdel-Moneim, A.M.E.; Asiry, K.A.; Mesalam, N.M.; Shafi, M.E.; Al-Harthi, M.A.; et al. Phytogenic Products and Phytochemicals as a Candidate Strategy to Improve Tolerance to Coronavirus. Front. Vet. Sci. 2020, 7, 1-18. [CrossRef]

35. Kapoor, R.; Sharma, B.; Kanwar, S.S. Antiviral Phytochemicals: An Overview. Biochem. Physiol. 2017, 6. [CrossRef]

36. Del Mar, C.; Doshi, P.; Hama, R.; Jones, M.; Jefferson, T.; Heneghan, C.; Onakpoya, I.; Howick, J. Neuraminidase inhibitors for influenza complications. Lancet 2014, 384, 1260-1261. [CrossRef] 
37. Rakib, A.; Sami, S.A.; Islam, M.A.; Ahmed, S.; Faiz, F.B.; Khanam, B.H.; Marma, K.K.S.; Rahman, M.; Uddin, M.M.N.; Nainu, F.; et al. Epitope-based immunoinformatics approach on nucleocapsid protein of severe acute respiratory syndrome-coronavirus-2. Molecules 2020, 25, 5088. [CrossRef] [PubMed]

38. Paintaud, G.; Alván, G.; Berninger, E.; Gustafsson, L.L.; Idrizbegovic, E.; Karlsson, K.K.; Wakelkamp, M. The concentration-effect relationship of quinine-induced hearing impairment. Clin. Pharmacol. Ther. 1994, 55, 317-323. [CrossRef]

39. Rakib, A.; Paul, A.; Ahmed, S.; Chy, M.N.U.; Sami, S.A.; Baral, S.K.; Majumder, M.; Tareq, A.T.; Amin, M.N.; Shahriar, A.; et al. Biochemical and computational approach of phytocompounds from Tinospora crispa in the management of COVID-19. Molecules 2020, 25, 3936. [CrossRef] [PubMed]

40. Li, J.Y.; Cao, H.Y.; Liu, P.; Cheng, G.H.; Sun, M.Y. Glycyrrhizic acid in the treatment of liver diseases: Literature review. Biomed. Res. Int. 2014, 2014, 872139. [CrossRef]

41. Heo, Y.A. Baloxavir: First Global Approval. Drugs 2018, 78, 693-697. [CrossRef] [PubMed]

42. Melendez, D.P.; Razonable, R.R. Letermovir and inhibitors of the terminase complex: A promising new class of investigational antiviral drugs against human cytomegalovirus. Infect. Drug Resist. 2015, 8, 269-277. [CrossRef] [PubMed]

43. Kaldor, S.W.; Kalish, V.J.; Davies, J.F.; Shetty, B.V.; Fritz, J.E.; Appelt, K.; Burgess, J.A.; Campanale, K.M.; Chirgadze, N.Y.; Clawson, D.K.; et al. Viracept (nelfinavir mesylate, AG1343): A potent, orally bioavailable inhibitor of HIV-1 protease. J. Med. Chem. 1997, 40, 3979-3985. [CrossRef]

44. Myers, R.P.; Shah, H.; Burak, K.W.; Cooper, C.; Feld, J.J. An update on the management of chronic hepatitis C: 2015 consensus guidelines from the Canadian Association for the Study of the Liver. Can. J. Gastroenterol. Hepatol. 2015, 29, 19-34. [CrossRef]

45. Rose, P.W.; Prlić, A.; Altunkaya, A.; Bi, C.; Bradley, A.R.; Christie, C.H.; Di Costanzo, L.; Duarte, J.M.; Dutta, S.; Feng, Z.; et al. The RCSB protein data bank: Integrative view of protein, gene and 3D structural information. Nucleic Acids Res. 2017, 45, D271-D281. [CrossRef] [PubMed]

46. DeLano, W.L. The PyMOL Molecular Graphics System, Version 1.1; Schrödinger LLC: New York, NY, USA, 2002. [CrossRef]

47. Studio, D. Dassault Systemes BIOVIA, Discovery Studio Modelling Environment, Release 4.5; Accelrys Softw. Inc.: San Diego, CA, USA, 2015.

48. Kaplan, W.; Littlejohn, T.G. Software review Swiss-PDB Viewer (Deep View). Brief. Bioinform. 2001, 2, 195-197. [CrossRef] [PubMed]

49. Kim, S.; Thiessen, P.A.; Bolton, E.E.; Chen, J.; Fu, G.; Gindulyte, A.; Han, L.; He, J.; He, S.; Shoemaker, B.A. PubChem substance and compound databases. Nucleic Acids Res. 2016, 44, D1202-D1213. [CrossRef]

50. Halgren, T.A. Performance of MMFF94*. J. Comput. Chem. 1996, 17, 490-519. [CrossRef]

51. Trott, O.; Olson, A.J. AutoDock Vina: Improving the speed and accuracy of docking with a new scoring function, efficient optimization, and multithreading. J. Comput. Chem. 2010, 31, 455-461. [CrossRef]

52. Daina, A.; Michielin, O.; Zoete, V. SwissADME: A free web tool to evaluate pharmacokinetics, drug-likeness and medicinal chemistry friendliness of small molecules. Sci. Rep. 2017, 7, 42717. [CrossRef]

53. Cheng, F.; Li, W.; Zhou, Y.; Shen, J.; Wu, Z.; Liu, G.; Lee, P.W.; Tang, Y. AdmetSAR: A comprehensive source and free tool for assessment of chemical ADMET properties. J. Chem. Inf. Model. 2012, 52, 3099-3105. [CrossRef]

54. Pires, D.E.V.; Blundell, T.L.; Ascher, D.B. pkCSM: Predicting small-molecule pharmacokinetic and toxicity properties using graph-based signatures. J. Med. Chem. 2015, 58, 4066-4072. [CrossRef]

55. Land, H.; Humble, M.S. YASARA: A tool to obtain structural guidance in biocatalytic investigations. Methods Mol. Biol. 2018, 1685, 43-67. [CrossRef]

56. Dickson, C.J.; Madej, B.D.; Skjevik, Å.A.; Betz, R.M.; Teigen, K.; Gould, I.R.; Walker, R.C. Lipid14: The amber lipid force field. J. Chem. Theory Comput. 2014, 10, 865-879. [CrossRef]

57. Krieger, E.; Vriend, G. New ways to boost molecular dynamics simulations. J. Comput. Chem. 2015, 36, 996-1007. [CrossRef] [PubMed]

58. Krieger, E.; Nielsen, J.E.; Spronk, C.A.E.M.; Vriend, G. Fast empirical pKa prediction by Ewald summation. J. Mol. Graph. Model. 2006, 25, 481-486. [CrossRef] [PubMed]

59. Swargiary, A.; Mahmud, S.; Saleh, M.A. Screening of phytochemicals as potent inhibitor of 3-chymotrypsin and papain-like proteases of SARS-CoV2: An in silico approach to combat COVID-19. J. Biomol. Struct. Dyn. 2020, 2020, 1-15. [CrossRef]

60. Mahmud, S.; Parves, M.R.; Riza, Y.M.; Sujon, K.M.; Ray, S.; Tithi, F.A.; Zaoti, Z.F.; Alam, S.; Absar, N. Exploring the potent inhibitors and binding modes of phospholipase A2 through in silico investigation. J. Biomol. Struct. Dyn. 2020, 38, 4221-4231. [CrossRef] [PubMed]

61. Bappy, S.S.; Sultana, S.; Adhikari, J.; Mahmud, S.; Khan, M.A.; Kibria, K.M.K.; Rahman, M.M.; Shibly, A.Z. Extensive Immunoinformatics study for the prediction of novel peptide-based epitope vaccine with docking confirmation against Envelope protein of Chikungunya virus: A Computational Biology Approach. J. Biomol. Struct. Dyn. 2020, 39, 1139-1154. [CrossRef]

62. Chowdhury, K.H.; Chowdhury, M.R.; Mahmud, S.; Tareq, A.M.; Hanif, N.B.; Banu, N.; Reza, A.S.M.A.; Emran, T.B.; SimalGandara, J. Drug Repurposing Approach against Novel Coronavirus Disease (COVID-19) through Virtual Screening Targeting SARS-CoV-2 Main Protease. Biology 2020, 10, 2. [CrossRef]

63. Khan, M.A.; Mahmud, S.; Alam, A.S.M.R.U.; Rahman, M.E.; Ahmed, F.; Rahmatullah, M. Comparative molecular investigation of the potential inhibitors against SARS-CoV-2 main protease: A molecular docking study. J. Biomol. Struct. Dyn. 2020, $2020,1-7$. [CrossRef] 
64. Mahmud, S.; Uddin, M.A.R.; Paul, G.K.; Shimu, M.S.S.; Islam, S.; Rahman, E.; Islam, A.; Islam, M.S.; Promi, M.M.; Emran, T.B.; et al. Virtual screening and molecular dynamics simulation study of plant-derived compounds to identify potential inhibitors of main protease from SARS-CoV-2. Brief. Bioinform. 2021, 22, 1402-1414. [CrossRef]

65. Islam, M.J.; Parves, M.R.; Mahmud, S.; Tithi, F.A.; Reza, M.A. Assessment of structurally and functionally high-risk nsSNPs impacts on human bone morphogenetic protein receptor type IA (BMPR1A) by computational approach. Comput. Biol. Chem. 2019, 80, 31-45. [CrossRef] [PubMed]

66. Samiul Islam, M.; Mahmud, S.; Sultana, R.; Dong, W. Identification and in silico molecular modelling study of newly isolated Bacillus subtilis SI-18 strain against S9 protein of Rhizoctonia solani. Arab. J. Chem. 2020, 13, 8600-8612. [CrossRef]

67. Mahmud, S.; Uddin, M.A.R.; Zaman, M.; Sujon, K.M.; Rahman, M.E.; Shehab, M.N.; Islam, A.; Alom, M.W.; Amin, A.; Akash, A.S.; et al. Molecular docking and dynamics study of natural compound for potential inhibition of main protease of SARS-CoV-2. J. Biomol. Struct. Dyn. 2020, 2020, 1-9. [CrossRef]

68. Pramanik, S.K.; Mahmud, S.; Paul, G.K.; Jabin, T.; Naher, K.; Uddin, M.S.; Zaman, S.; Saleh, M.A. Fermentation optimization of cellulase production from sugarcane bagasse by Bacillus pseudomycoides and molecular modeling study of cellulase. Curr. Res. Microb. Sci. 2021, 2, 100013. [CrossRef]

69. Rakib, A.; Nain, Z.; Sami, S.A.; Mahmud, S.; Islam, A.; Ahmed, S.; Siddiqui, A.B.F.; Babu, S.M.O.F.; Hossain, P.; Shahriar, A.; et al. A molecular modelling approach for identifying antiviral selenium-containing heterocyclic compounds that inhibit the main protease of SARS-CoV-2: An in silico investigation. Brief. Bioinform. 2021, 22, 1476-1498. [CrossRef]

70. Tsaioun, K.; Bottlaender, M.; Mabondzo, A. ADDME-Avoiding Drug Development Mistakes Early: Central nervous system drug discovery perspective. BMC Neurol. 2009, 9, S1. [CrossRef] [PubMed]

71. Islam, M.R.; Hoque, M.N.; Rahman, M.S.; Alam, A.S.M.R.U.; Akther, M.; Puspo, J.A.; Akter, S.; Sultana, M.; Crandall, K.A.; Hossain, M.A. Genome-wide analysis of SARS-CoV-2 virus strains circulating worldwide implicates heterogeneity. Sci. Rep. 2020, 10, 14004. [CrossRef]

72. Ton, A.T.; Gentile, F.; Hsing, M.; Ban, F.; Cherkasov, A. Rapid Identification of Potential Inhibitors of SARS-CoV-2 Main Protease by Deep Docking of 1.3 Billion Compounds. Mol. Inform. 2020, 39, 2000028. [CrossRef] [PubMed]

73. Wang, J. Fast Identification of Possible Drug Treatment of Coronavirus Disease-19 (COVID-19) Through Computational Drug Repurposing Study. J. Chem. Inf. Modeling 2020, 60, 3277-3286. [CrossRef] [PubMed]

74. Pillaiyar, T.; Manickam, M.; Namasivayam, V.; Hayashi, Y.; Jung, S.H. An overview of severe acute respiratory syndromecoronavirus (SARS-CoV) 3CL protease inhibitors: Peptidomimetics and small molecule chemotherapy. J. Med. Chem. 2016, 59, 6595-6628. [CrossRef]

75. Rakib, A.; Sami, S.A.; Mimi, N.J.; Chowdhury, M.M.; Eva, T.A.; Nainu, F.; Paul, A.; Shahriar, A.; Tareq, A.M.; Emon, N.U.; et al. Immunoinformatics-guided design of an epitope-based vaccine against severe acute respiratory syndrome coronavirus 2 spike glycoprotein. Computers Biol. Med. 2020, 124, 103967. [CrossRef]

76. Dai, W.; Zhang, B.; Jiang, X.M.; Su, H.; Li, J.; Zhao, Y.; Xie, X.; Jin, Z.; Peng, J.; Liu, F.; et al. Structure-based design of antiviral drug candidates targeting the SARS-CoV-2 main protease. Science 2020, 368, 1331-1335. [CrossRef]

77. Khan, S.A.; Zia, K.; Ashraf, S.; Uddin, R.; Ul-Haq, Z. Identification of Chymotrypsin-like Protease Inhibitors of SARS-CoV-2 Via Integrated Computational Approach. J. Biomol. Struct. Dyn. 2021, 39, 2607-2616. [CrossRef] [PubMed]

78. Harapan, H.; Ryan, M.; Yohan, B.; Abidin, R.S.; Nainu, F.; Rakib, A.; Jahan, I.; Emran, T.B.; Ullah, I.; Panta, K.; et al. COVID-19 and dengue: Double punches for dengue-endemic countries in Asia. Rev. Med. Virol. 2021, 31, e2161. [CrossRef] [PubMed]

79. Anand, K.; Palm, G.J.; Mesters, J.R.; Siddell, S.G.; Ziebuhr, J.; Hilgenfeld, R. Structure of coronavirus main proteinase reveals combination of a chymotrypsin fold with an extra $\alpha$-helical domain. EMBO J. 2002, 21, 3213-3224. [CrossRef] [PubMed]

80. Lu, I.L.; Mahindroo, N.; Liang, P.H.; Peng, Y.H.; Kuo, C.J.; Tsai, K.C.; Hsieh, H.P.; Chao, Y.S.; Wu, S.Y. Structure-based drug design and structural biology study of novel nonpeptide inhibitors of severe acute respiratory syndrome coronavirus main protease. $J$. Med. Chem. 2006, 49, 5154-5161. [CrossRef]

81. Jin, Z.; Du, X.; Xu, Y.; Deng, Y.; Liu, M.; Zhao, Y.; Zhang, B.; Li, X.; Zhang, L.; Peng, C.; et al. Structure of Mpro from SARS-CoV-2 and discovery of its inhibitors. Nature 2020, 582, 289-293. [CrossRef]

82. Hengphasatporn, K.; Garon, A.; Wolschann, P.; Langer, T.; Yasuteru, S.; Huynh, T.N.T.; Chavasiri, W.; Saelee, T.; Boonyasuppayakorn, S.; Rungrotmongkol, T. Multiple virtual screening strategies for the discovery of novel compounds active against dengue virus: A hit identification study. Sci. Pharm. 2020, 88, 2. [CrossRef]

83. Maia, E.H.B.; Assis, L.C.; de Oliveira, T.A.; da Silva, A.M.; Taranto, A.G. Structure-Based Virtual Screening: From Classical to Artificial Intelligence. Front. Chem. 2020, 8, 343. [CrossRef] [PubMed]

84. Sousa, S.F.; MFSA Cerqueira, N.; Fernandes, P.A.; Joao Ramos, M. Virtual Screening in Drug Design and Development. Comb. Chem. High Throughput Screen. 2010, 13, 442-453. [CrossRef] [PubMed]

85. Schichet, B.K. Virtual screening of chemical libraries. Nature 2004, 432, 862-865. [CrossRef] [PubMed]

86. Zhang, X.; Li, J.; Li, Y.; Liu, Z.; Lin, Y.; Huang, J. An Anti-melanogenic effects of epigallocatechin-3-gallate (EGCG), epicatechin3-gallate (ECG) and gallocatechin-3-gallate (GCG) via down-regulation of cAMP/CREB/MITF signaling pathway in B16F10 melanoma cells. Fitoterapia 2020, 145, 104634. [CrossRef] [PubMed]

87. Pan, M.H.; Chiou, Y.S.; Wang, Y.J.; Ho, C.T.; Lin, J.K. Multistage carcinogenesis process as molecular targets in cancer chemoprevention by epicatechin-3-gallate. Food Funct. 2011, 2, 101-110. [CrossRef] 
88. Chen, T.; Yang, Y.; Zhu, S.; Lu, Y.; Zhu, L.; Wang, Y.; Wang, X. Inhibition of A $\beta$ aggregates in Alzheimer's disease by epigallocatechin and epicatechin-3-gallate from green tea. Bioorg. Chem. 2020, 105, 104382. [CrossRef]

89. Huang, S.F.; Horng, C.T.; Hsieh, Y.S.; Hsieh, Y.H.; Chu, S.C.; Chen, P.N. Epicatechin-3-gallate reverses TGF- $\beta 1$-induced epithelialto-mesenchymal transition and inhibits cell invasion and protease activities in human lung cancer cells. Food Chem. Toxicol. 2016, 94, 1-10. [CrossRef] [PubMed]

90. Kumar, Y.; Singh, H.; Patel, C.N. In silico prediction of potential inhibitors for the Main protease of SARS-CoV-2 using molecular docking and dynamics simulation based drug-repurposing. J. Infect. Public Health 2020, 3, 1210-1213. [CrossRef]

91. Rabaan, A.A.; Al-Ahmed, S.H.; Muhammad, J.; Khan, A.; Sule, A.A.; Tirupathi, R.; Mutair, A.A.; Alhumaid, S.; Al-Omari, A.; Dhawan, M.; et al. Role of Inflammatory Cytokines in COVID-19 Patients: A Review on Molecular Mechanisms, Immune Functions, Immunopathology and Immunomodulatory Drugs to Counter Cytokine Storm. Vaccine 2021, 9, 436. [CrossRef]

92. Akihisa, T.; Yasukawa, K.; Oinuma, H.; Kasahara, Y.; Yamanouchi, S.; Takido, M.; Kumaki, K.; Tamura, T. Triterpene alcohols from the flowers of compositae and their anti- inflammatory effects. Phytochemistry 1996, 43, 1255-1260. [CrossRef]

93. Meyer, E.A.; Castellano, R.K.; Diederich, F. Interactions with Aromatic Rings in Chemical and Biological Recognition. Angew. Chemie Int. Ed. 2003, 42, 4120. [CrossRef]

94. Rabaan, A.A.; Al-Ahmed, S.H.; Garout, M.A.; Al-Qaaneh, A.M.; Sule, A.A.; Tirupathi, R.; Mutair, A.A.; Alhumaid, S.; Al-Omari, A.; Hasan, A.; et al. Diverse Immunological Factors Influencing Pathogenesis in Patients with COVID-19: A Review on Viral Dissemination, Immunotherapeutic Options to Counter Cytokine Storm and Inflammatory Responses. Pathogens 2021, 10, 565. [CrossRef] [PubMed]

95. Abramson, H.N. The lipogenesis pathway as a cancer target. J. Med. Chem. 2011, 54, 5615-5638. [CrossRef]

96. Kürbitz, C.; Heise, D.; Redmer, T.; Goumas, F.; Arlt, A.; Lemke, J.; Rimbach, G.; Kalthoff, H.; Trauzold, A. Epicatechin gallate and catechin gallate are superior to epigallocatechin gallate in growth suppression and anti-inflammatory activities in pancreatic tumor cells. Cancer Sci. 2011, 102, 728-734. [CrossRef] [PubMed]

97. Jiang, F.; Chen, W.; Yi, K.; Wu, Z.; Si, Y.; Han, W.; Zhao, Y. The evaluation of catechins that contain a galloyl moiety as potential HIV-1 integrase inhibitors. Clin. Immunol. 2010, 137, 347-356. [CrossRef]

98. Strobel, P.; Allard, C.; Perez-Acle, T.; Calderon, R.; Aldunate, R.; Leighton, F. Myricetin, quercetin and catechin-gallate inhibit glucose uptake in isolated rat adipocytes. Biochem. J. 2005, 386, 471-478. [CrossRef]

99. Rabaan, A.A.; Tirupathi, R.; Sule, A.A.; Aldali, J.; Al Mutair, A.; Alhumaid, S.; Muzaheed; Gupta, N.; Koritala, T.; Adhikari, R.; et al. Viral dynamics and real-time RT-PCR Ct values correlation with disease severity in COVID-19. Diagnostics 2021, 11, 1091. [CrossRef]

100. Tallei, T.E.; Tumilaar, S.G.; Niode, N.J.; Kepel, B.J.; Idroes, R.; Effendi, Y.; Sakib, S.A.; Emran, T.B. Potential of Plant Bioactive Compounds as SARS-CoV-2 Main Protease (Mpro) and Spike (S) Glycoprotein Inhibitors: A Molecular Docking Study. Scientifica 2020, 2020, 6307457. [CrossRef]

101. Bhowmick, S.; Saha, A.; Osman, S.M.; Alasmary, F.A.; Almutairi, T.M.; Islam, M.A. Structure-based identification of SARS-CoV-2 main protease inhibitors from anti-viral specific chemical libraries: An exhaustive computational screening approach. Mol. Divers. 2021, 2021, 1-19. [CrossRef]

102. Keretsu, S.; Bhujbal, S.P.; Cho, S.J. Rational approach toward COVID-19 main protease inhibitors via molecular docking, molecular dynamics simulation and free energy calculation. Sci. Rep. 2020, 10, 17716. [CrossRef]

103. Marinho, E.M.; Batista de Andrade Neto, J.; Silva, J.; Rocha da Silva, C.; Cavalcanti, B.C.; Marinho, E.S.; Nobre Júnior, H.V. Virtual screening based on molecular docking of possible inhibitors of Covid-19 main protease. Microb. Pathog. 2020, $148,104365$. [CrossRef] [PubMed] 